\title{
correspondence
}

\section{Austrian science journalists were warned}

SIR,-As one of the people principally involved in disclosing the fraudulent activities of Schaden (Austrian science minister attacks science journalists in fraud case' 24 November, page 292), 1 should like to point out that in 1973 I warned Austrian scientists and science journalists about the questionable 'discoveries' of Schaden and Celta. Unfortunately, as the Science Ministry's document demonstrates, this was to little avail.

The purpose of the document and the Ministry's previous interventions and warnings, was to protect the scientific community from public discredit on account of a charlatan's 'research'. It was also to serve as a constructive warning to scientific journalists not to take every apparent scientific 'break-through' at its face value.

If the Science Ministry's document lacks thoroughness, this will certainly be supplied by the court's records of the Schaden case.

Yours faithfully, WiLHELM GrimbURG

Vienna, Austria

\section{A third world energy view}

SIR,--Effective use of the world's finite cheap oil reserves to save time and effort deserves a broader discussion than that given by Alvin $\mathrm{M}$. Weinberg (20 October, page 638). Efficiency of the conversion of energy into time saved is highly variable. To travel 15 miles, for large numbers of people, means walking in the tropical heat carrying luggage and taking, say 5 hours. To be lucky enough to have a small motorcycle (and do the journey in 30 minutes on 0.1 gallons of fuel) saves 45 gruelling man hours per gallon. To then change to a large car (and come back at 90 miles per hour using 1 gallon of fuel) will only save a further 0.37 man hours per gallon.

The assertion that "a free society allows each of us to make the choice" and "economics. . . integrates all these .. . judgments" means that the rich have the right to decide. But when availability of cheap oil begins to decrease these judgments will, no doubt, be re-evaluated, and those who make them now thus carry a heavy respon- sibility. Surely they will be expected to justify their judgments when others reach the position where they could use oil but find that it has all been carelessly squandered to save milliseconds of millionaire's time per gallon.

$$
\begin{aligned}
& \text { Yours faithfully, } \\
& \text { M. D. Melamed } \\
& \text { Maputo, Mozambique }
\end{aligned}
$$

\section{Desert rainfall}

Sir,-J. L. Deaton (24 November, page 294) makes several statements concerning our article (19 May, page 192) with which we disagree. He claims, in particular, that "in no sense is the mean too large". There is, however, a well defined sense in which the mean of a positively skewed distribution (for example, precipitation) is "too large". Specifically, it may be desired that a statistic, to be taken as a measure of central tendency, has the property that either it represents the midpoint of the distribution (that is the median), or that it represents the value of the distribution which is most likely to occur (that is the mode). If the distribution is positively skewed, then the mean is larger than the values satisfying either of these properties.

Deaton also claims that the mean "is quite indicative of how much rain commonly falls in most regions-even Gao and Niamey." But the mean, at least in some sense, is not at all indicative of how much rain "commonly" falls in the Sahel. As an example, consider the Gao August precipitation data used in our article: only 4 of the 35 observations (11\%) fall within $10 \%$ of the mean; 23 of the 35 observations $(66 \%)$ fall below the mean; and the mode (or most 'common' value) is $80.0 \mathrm{~mm}$, substantially less than the mean of $100.9 \mathrm{~mm}$.

Deaton states that "there seems to be only a slight tendency for the degree of skewness to increase as the average amount of precipitation decreases". This statement contradicts the results of studies on this issue in the climatological literature (Arnold Court in Climates of North America. World Survey of Climatology 11, 212 (Elsevier, Amsterdam 1974)). While it is true that all precipitation distributions are at least slightly positively skewed, there is a marked tendency for the degree of skewness to increase as the mean precipitation decreases.

Finally, Deaton asks for documentation of the observation that "recent weather tends to influence perceptions more heavily than earlier weather and wet spells more heavily than dry ones". The documentation for this statement is a quote from J. C. Caldwell "Rainfall Statistics, Droughts, and Desertification in the Sahel," Desertification, 84 (Westview Press, Boulder, Colorado 1977).

Yours faithfully,
MiCHaEl H. GLantz
Richard W. KaTz
National Center for
Atmospheric Research
Boulder, Colorado USA

\section{IQ or intelligence type?}

SIR,- The controversy over race and IQ is clouded by the lack of culturally neutral testing procedures. Who would we be to say that a community of blacks who tested slightly lower than comparable whites were not immeasurably superior in forms of mental ability not emphasised in the test procedures? A slight mean shift from one community to another would doubtless be given more weight than it deserves, and it would still be possible (if its Gaussian distribution was shallower) for the 'less endowed' community to provide more geniuses than its counterpart Furthermore, the difference between the two means would certainly be less than that between any two members of either group that you might encounter in the street, but would this be taken into account by those with political motivations? Data may be used to substantiate whatever case and in an area like this the phenomenon could have serious consequences. The "compensatory advantages" Sir Andrew Huxley cites in his address to the British Association annual meeting would soon be seen as racially-discriminative favouritism, and is it really so likely that humane considerations would moderate the debate? We take scientific findings much less seriously than it is popular to imagine: the new evidence in fields such as psychokinesis, spoon-bending, E.S.P., and tobacco smoking has done little to alter the attitudes of those with convictions of convenience that contradict the specialist conclusions, and there are still 
eminent scientists who refuse to accept evolutionary theory and rely instead on more metaphysical alternatives. Scientific findings do not alter human belief so readily.

Huxley says that it is a characteristic of research that its outcome is not known in advance. That is so: but it is a presupposition of outcome that often motivates research, which may bias its interpretation, and which makes it possible that results will not alter preconceptions. In the correspondence for the same issue in which Huxley's reply to Nature's earlier editorial on his address appears (29 September, page 366), C. J. Robbins subscribes to the widely-held view that science sets out to falsify theories through experimentation. As the pages of Nature show, this is rarely true; the commonest motivation in research might well be exactly the converse.

The concept of IQ itself is a simplistic parameter which assumes that cognitive, perceptual, deductive and mathematical abilities go hand in hand, whereas our selection of individuals (for employment, etc.) shows this cannot be the case. We accept that brilliant mathematicians may be absent-minded, that musicians may be hopeless fine artists, scientists poor communicators. Why then do we hear so little about what we might call intelligence type? Until we have evolved realistic codes of criteria for assessment that reconcile mental measurements with the realities of life I believe we should postpone spurious research into racially-determined $I Q$, and recognise it as being ill-founded and premature.

In my view this is the most objective manner in which one could admit the limitations of contemporary science, and the irrelevance of research findings to those determined to subscribe to their own beliefs; these two are topics that are ripe for research.

Yours faithfully, BRIAN J. FORD

Science Unit, Cardiff, Wales

\section{Soviet genetics}

SIR,- As far as I know, gerontologists have been wary, over the years, of passing opinions on human genetics and on human genetics programmes. I was therefore very interested to read the review by Dr Zhores Medvedev, a noted gerontologist, on the development of human genetics in the USSR since Lysenko ('Soviet genetics: new controversy', 28 July, page 285).

The review bears a title which is frightening for anyone knowing the history of genetics in that country. A new controversy is hardly needed at this stage. The international congress of genetics is due this year in Moscow and even calling attention to controversy might cause unpredictable side effects. Fortunately, renewed anxiety for the fate of human genetics in the USSR seems premature at this stage; the review gives a brief account of the re-emergence of the discipline, and for the rest is an all-out attack on the retiring director of the Institute of General Genetics of the Academy of Sciences, Dr N. Dubinin.

Of those who reinstated human genetics in the USSR Medvedev writes: "all of them were void of real practical knowledge of human or medical genetics", and one is left to wonder how they happened to have the courage to do it. Furthermore, if those who only had knowledge of drosophila genetics, of radiation, rodents, cytology and theoretical human genetics can be criticised for their contribution what can a gerontologist say about human genetics; in what position is he to pass value judgements?

Dr Medvedev, although he does not say so, must have participated in the discussions, since he says they were peaceful, albeit not very productive. Again one wonders how the new Institute of Medical Genetics was established as an outcome of such a lack of productivity.

One cannot help noticing the amount of negative emphasis put by Dr Medvedev on an action which tended to reconstruct human genetics. It is my opinion that, since these negative emphases diminish the whole operation, he should produce the evidence on which they are based. What, for example, is the evidence that D. K. Beliaev had been appointed in 1976 president of the 1978 Congress? This is puzzling, because Beliaev is general secretary, and Tsitsin (wheat hybrids at Lysenko's time) is president.

The part of the review which is devoted to Dubinin is less important. Dubinin, as others, went through the bitter years of the Soviet geneticists and survived. At present, he seems to have developed his own personal views on the inheritance of human abilities; these views are questionable but since they have been publicly castigated, they are not official views which might endanger those not sharing them. It seems arbitrary to associate them with a controversy which might harm human genetics; he is entitled to his opinions, no less than Medvedev to his own and I to mine. So far as some of Dubinin's work on human genetics is concerned, and so far as I can read, he has recently used erroneous techniques in the study of multivariation in quantitative traits in man. However, it might well be that, as director, he signs work from his institute which might be beyond the capacity of his technical judgment (for example Dokl. Akad. Nauk. 230, 4: 957-960, 1976).

I believe that the most contradictory aspect of Medvedev's review is that Dubinin is turning against the programme he helped to start a short time ago, I believe that the accusation Medvedev makes, that "Dubinin is working hard to suppress by all possible means the development of genuine research in the field of human genetics in the USSR", and which amounts to public condemnation, is so important, that Medvedev is bound to produce evidence for it. It would be sad for those who have helped in the reconstruction, even for those who have given a minimal contribution, if attempts to create new conflicts hinder development. Human genetics is a hot science to handle: it seems useless to make it even hotter. After all, state and interstate budgets for human genetics can be cut easily, both east and west of Greenwich. Yours faithfully, ITALO BARRAI

Universita di Ferrara,

Italy

\section{The Messinian salinity crisis}

SIR,-Lines in reply to an anonymous critic (20 October, page 646)

When composing lyric verse

Be it critical or worse

It is wise to be quite certain of one's ground,

And not to call absurd

Quite a harmless little word

Lest its meaning be not simple but profound.

Crises evaporitic

Irritate our nameless critic

Rightly so, had we but meant what he implied,

But salinity increased

Until crisis point was reached

Whereupon the fauna disappeared or died.

Oh, 'tis pity I declare

That whatever we prepare

And however clear the message that we send,

There are always colleagues who

Having little else to do

Criticise us when they do not comprehend.

N.B.-The term 'Salinity Crisis' was, I believe, coined by Ruggieri (Systematics Association Publication No. 7 (eds Adams, C. G. and Ager, D. V.), 283-290 (London, 1967)) and referred to the apparent extinction of the marine faunas of the western Mediterranean in Messinian times. Your faithfully, C. G. ADAMS

British Museum (Natural History), London 